\title{
Economic Slowdown and Stabilization Policy
}

HE PACE OF real economic activity remains sluggish, as the response to last year's monetary and fiscal restraint continues. Despite the slowdown in production and employment, the pace of inflation has not yet moderated significantly.

Major questions regarding the economy include: (1) How long will real economic activity continue so

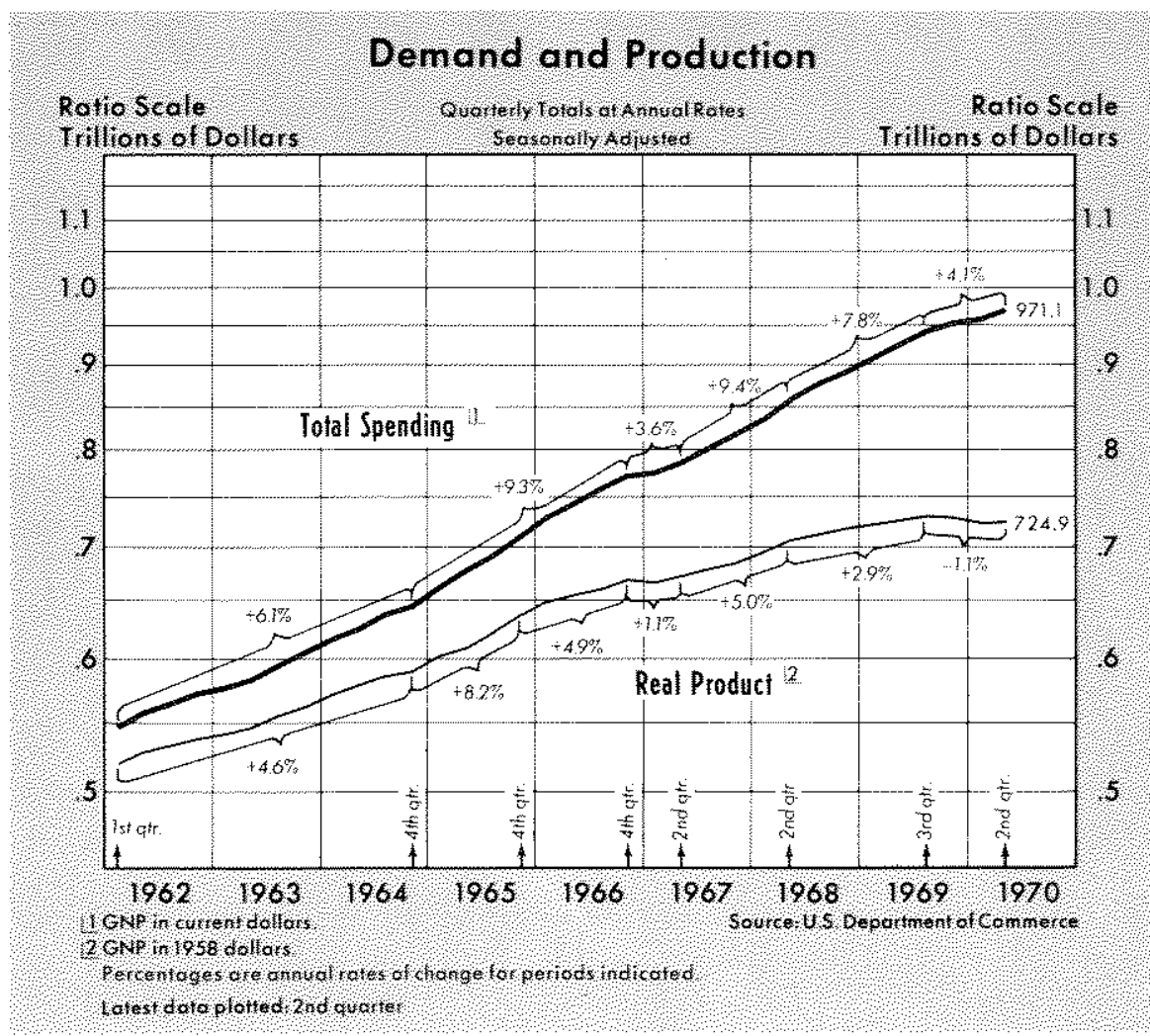

sluggish and, once recovery begins, how strong will it be? (2) What are the prospects for an easing in inflationary pressures? The course of prices and output in coming quarters will be influenced greatly by monetary and fiscal actions which have already occurred, as well as by forthcoming actions.

\section{Fitherpot of aconomic Soundotas}

Growth of total spending for goods and services began slowing in late 1969, in response to antiinflationary monetary and fiscal actions. Such spending rose at a 4 per cent annual rate from third quarter 1969 to second quarter 1970 , following an 8 per cent average rate of advance in the previous five quarters. Continued rapid increases in prices, reflecting excessive total demand in the previous five years, along with the reduction in growth of total spending, resulted in a decline in real product. Total real output (GNP adjusted for changes in prices), which rose at a 3 per cent average annual rate in the five quarters ending third quarter 1969 , declined at a 1 per cent rate from third quarter 1969 to second quar- 
ter 1970. Industrial production, which is usually more sensitive than total output to changes in total spending, has decreased at a 3 per cent average annual rate since mid-1969. This decline in production follows a rise of 4.9 per cent from mid-1968 to mid1969 and a 6.5 per cent gain in the previous year.

Moderated growth of total spending and output first had little effect on employment growth which did not slow appreciably until early this year. Firms apparently were reluctant to reduce their work forces until the reduced growth of total spending proved more than temporary. By historical standards, the labor market was very tight early in 1969 , with almost 65 per cent of the population of labor force age employed, compared with an average of 62 per cent in the Fifties and early Sixties. Because labor had been unusually scarce, the competitive costs of hiring and training personnel probably contributed to employer reluctance to lay off workers in late 1969 and early 1970. Reflecting this lag in adjustment of the work force to changes in the growth of total spending, total employment did not slow significantly until March of this year, but has since declined at a 2 per cent rate. Nevertheless, 64 per cent of the population of working force age has been employed this summer, a greater proportion than at any time in the Fifties and Sixties prior to 1967.

Slowing of growth in spending, output and employment has not yet resulted in a clear reduction in the rate of increase of prices. Inflation apparently is no longer accelerating, but a decline in the rate of advance of prices has not yet been firmly established. The broadest measure of prices, the implicit price deflator for GNP, increased at a 5.4 per cent annual rate in the first half of 1970, about the same as in the last half of 1969 . Consumer prices have increased at about a 6 per cent rate since December, about

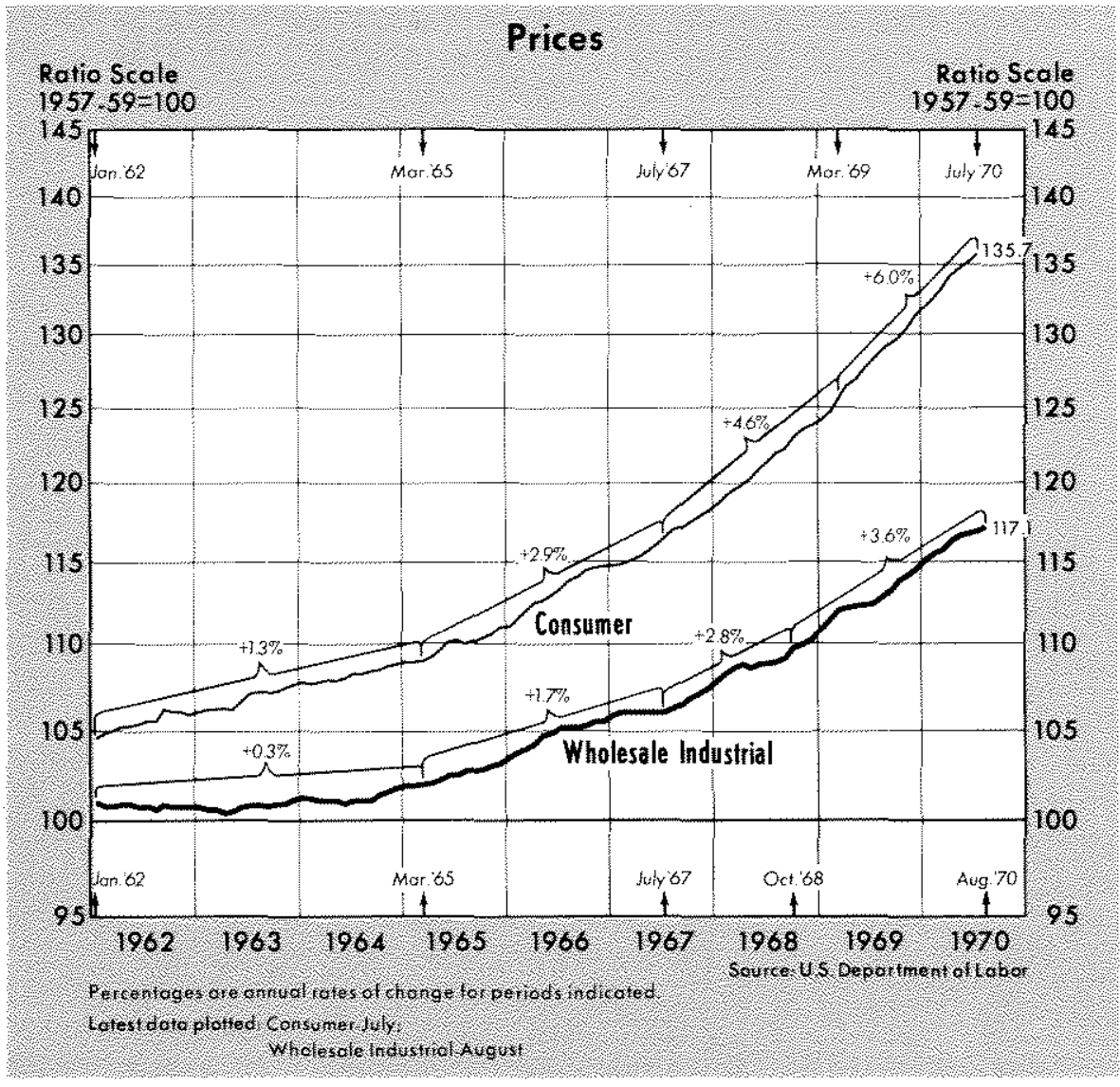

the same as in the previous year. In contrast, consumer prices rose at a 3.8 per cent average rate in 1967 and 1968 and at a 1.2 per cent rate in the $1961-64$ period. Wholesale industrial prices have risen at about a 4 per cent rate since last fall, about the same as in the previous year.

Continued rapid inflation in the face of moderated growth of spending, output and employment is consistent with past experience in the U.S. economy (Table I).
Toble:

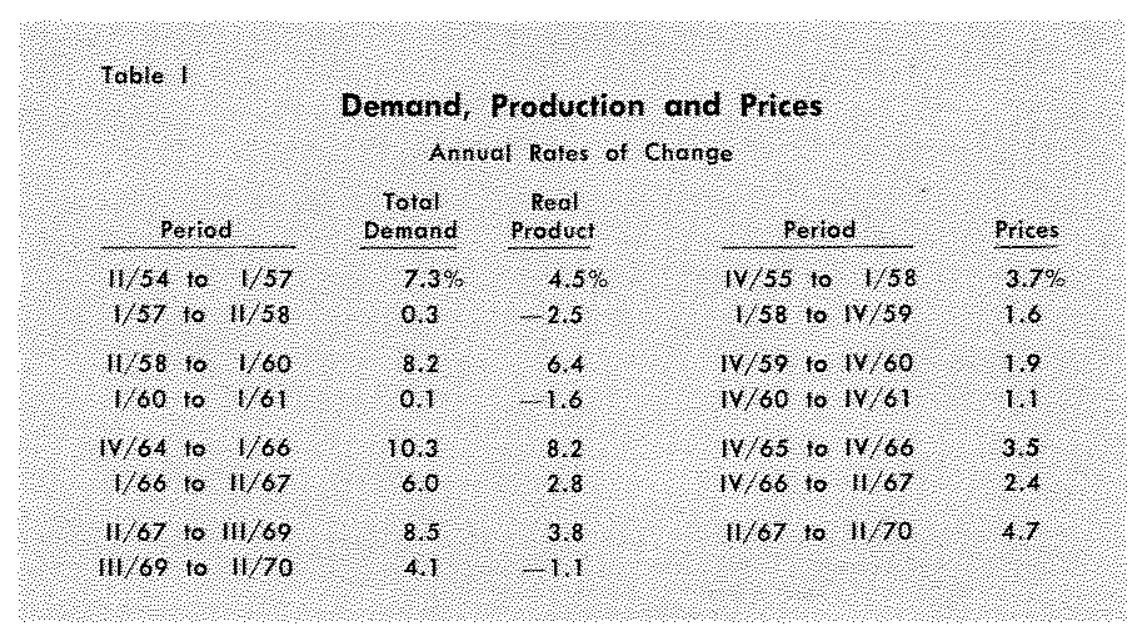


For example, in 1957-58 the rate of price increase did not begin to recede until about a year after output growth slowed, and in 1960-61 the lag was about three quarters. The main difference between the most recent period and other periods of slowdown is the greater momentum that inflation was allowed to achieve in the 1964-69 period than in previous periods. The length of time required to achieve relative price stability, such as during the 1961-64 period, is likely to be considerable. Not only has in " flation been allowed to achieve rates higher than in other inflationary periods in the postwar U.S. economy, but the degree of monetary and fiscal restraint has been less than in other such periods.

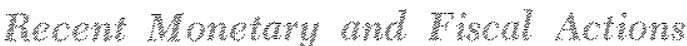

The course of spending, output and prices in recent quarters appears to have responded normally to monetary and fiscal actions. Economic developments in the second half of 1970 will depend in large measure on policy actions already taken in the first half of the year. Both monetary and fiscal actions have been more expansive in 1970 than in 1969, though such stimulative policy actions have persisted for only a relatively short period.

Fiscal actions - Federal budget actions in the first half of 1970 were dominated by several factors affecting disposable income: a 6 per cent pay increase for Federal employees, retroactive to the beginning of the year; an increase in the Social Security benefit schedule, also retroactive; and a reduction in the tax surcharge on January 1. Reflecting these actions, the high-employment budget moved from a surplus of about $\$ 11$ billion in the year ending in first quarter

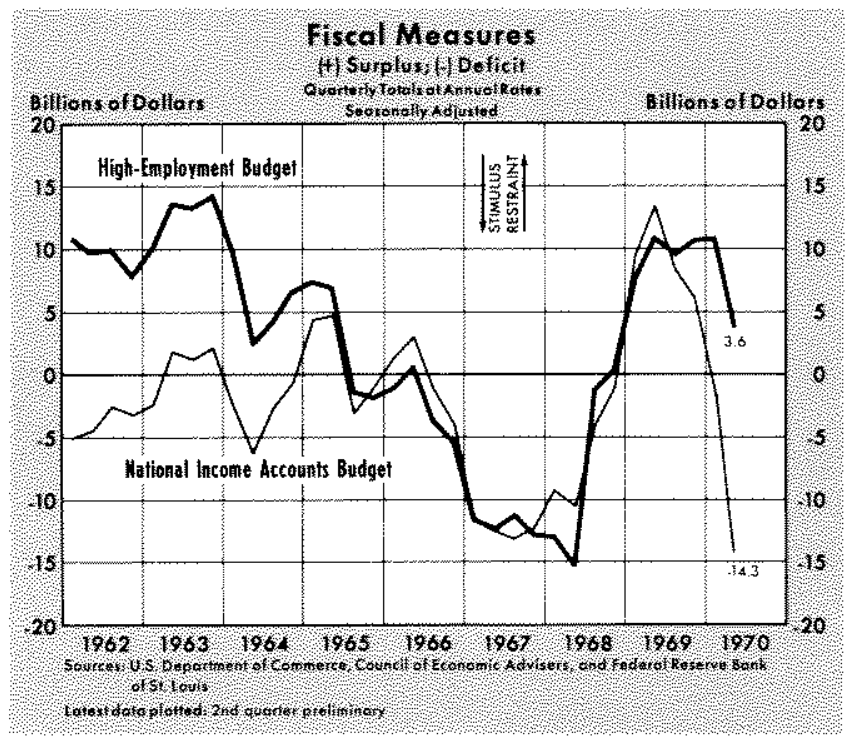

1970 to a $\$ 3.6$ billion rate in the second quarter of 1970. This reduced rate of surplus was in marked contrast to the $\$ 10$ billion average annual rate of deficit in the high-employment budget in 1967 and 1968.

The national income accounts budget moved from a $\$ 9$ billion surplus in 1969 to a $\$ 14$ billion annual rate of deficit in the second quarter of this year. This budget, in contrast with the high-employment budget, is inffuenced by variations in growth of total spending in the economy, as well as changes in Federal expenditures and tax rates. Consequently, the national income accounts budget is misleading as a measure of fiscal actions. Reduced growth of total spending, and thus of income and profits, contributed to a drop in Federal tax receipts at a $\$ 5$ billion annual rate from fourth quarter 1969 to second quarter 1970.

Monetary actions - Monetary actions became relatively expansionary in early 1970 . The money stock rose at a 5 per cent amnual rate from the three months ending February 1970 to the three months ending in August, after changing little in the second half of 1969 .

Acceleration of money stock growth reflected more rapid expansion of Federal Reserve credit and bank reserves since February. Federal Reserve credit grew at a 7 per cent annual rate from February to August, compared with a 3 per cent increase in the previous year.

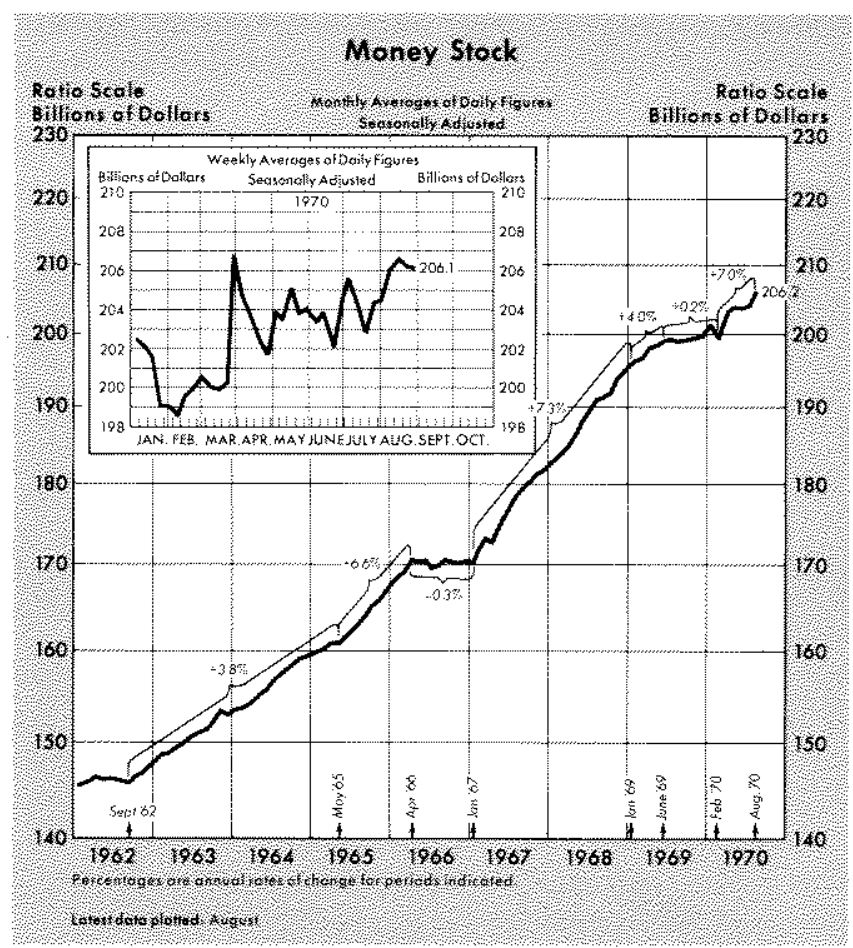




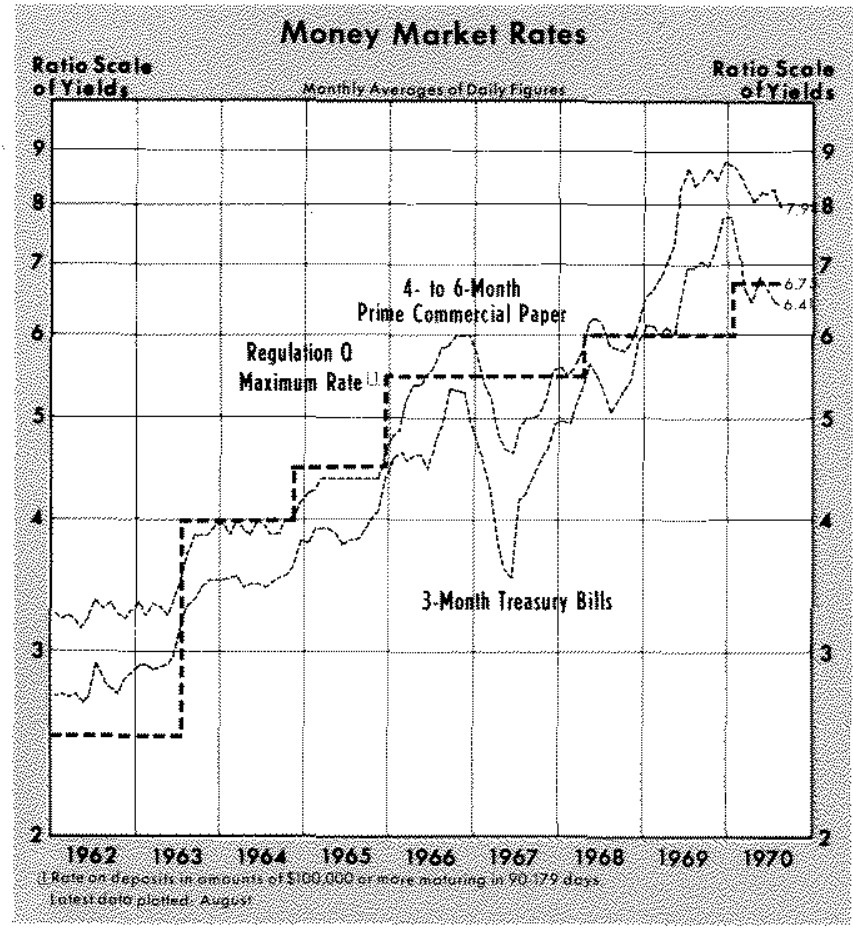

More rapid expansion of Federal Reserve credit and the money stock since early 1970 has been accompanied by a sharp acceleration in the growth of time deposits, reflecting primarily a decline in market interest rates and changes in Regulation Q. This regulation has been changed twice this year (January 21 and June 24), each time in the direction of increasing the maximum rates which banks are permitted to offer on time deposits. As a result, banks became more competitive in bidding for funds, and time deposits at commercial banks have increased sharply since January. Total time deposits increased at an 11.5 per cent annual rate from January to June. Since June, these deposits have increased yet more rapidly, at a 37 per cent annual rate, reflecting the suspension of ceilings on rates paid for large certificates of deposit maturing in 30 to 89 days. Over half of the increase in time deposits since Jume has been in large certificates of deposit. Since January, these CD's outstanding at commercial banks have increased by $\$ 9$ billion, offsetting a large part of the $\$ 13$ billion decline from December 1968 to January 1970.

The large inflow of time deposits has been accompanied by an increase in bank credit at a 10 per cent annual rate since February. Over the previous year, the level of bank credit remained essentially unchanged. The recent upsurge of bank credit reflects partly an increase in Federal Reserve credit, and to that extent represents an increase in total credit in the economy. But the bulk of the increase in bank credit

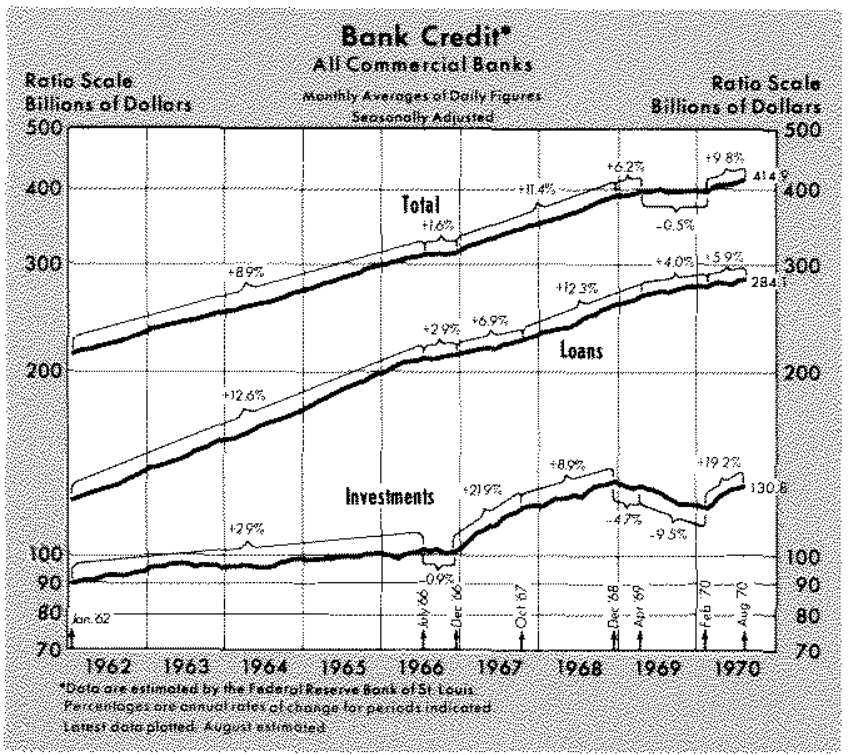

reflects rather a reintermediation of funds previously flowing through nonbank credit channels. From late 1968 to early 1970, banks were not able to compete effectively for funds with open market interest rates which were generally above the Regulation $Q$ ceilings. With the increase in ceilings in 1970 and the general decline in short-term market interest rates, banks have been able to bid funds away from these other markets.

The yield on Treasury bills fell from a 7.87 per cent average in January to 6.41 per cent in August. Longterm corporate rates, however, rose slightly on balance; the rate on corporate Aaa bonds rose from 7.91 per cent in January to 8.13 per cent in August.

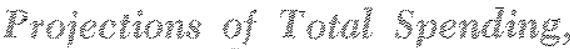

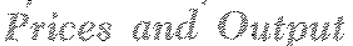

Monetary and fiscal actions of recent months will continue to affect total spending in the second half of 1970 , but a more complete assessment of forthcoming developments requires assumptions about the future course of monetary and fiscal actions.

The pattern of fiscal actions for the year ending June 30, 1971 ean be assessed by looking at Federal budget plans for that period. Current estimates indicate Federal spending in fiscal 1971 will be about 5 per cent higher than last year. The large increase in expenditures in the second quarter of calendar 1970 was associated with the Government pay increase and rise in Social Security benefits, and is not considered indicative of a trend. To provide projections of total spending, prices, and output beyond mid-1971, Federal expenditures were assumed to grow at a 6 per cent annual rate after mid-1971. 


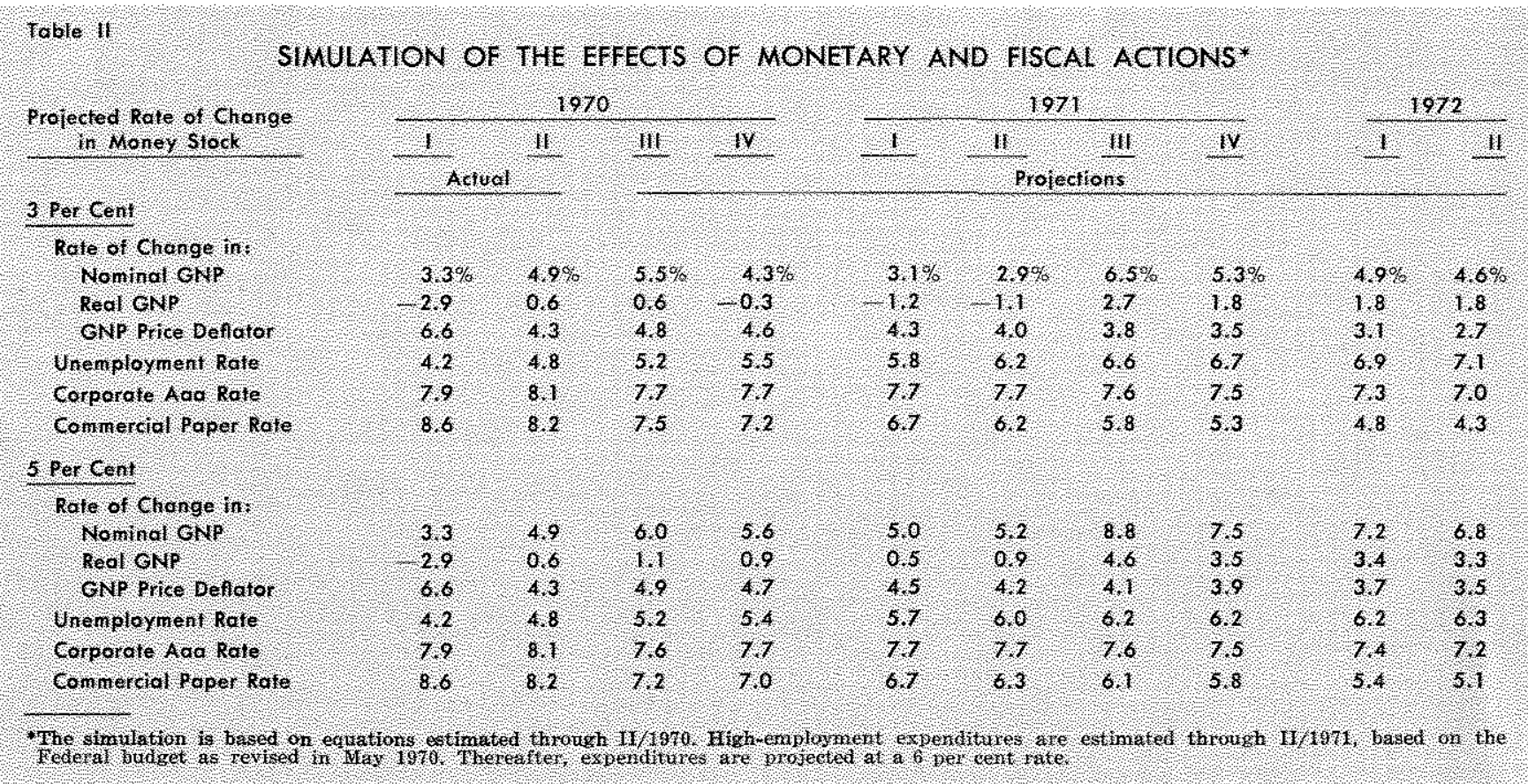

For purposes of projecting total spending, two alternative courses of monetary action are considered. A 5 per cent rate of growth in money for the two-year period starting in second quarter 1970 would be considered as a moderately stimulative course of monetary action. A 3 per cent rate of monetary expansion for the next two years would be a moderately restrictive monetary policy.

An optimal rate of monetary expansion must be selected on the basis of a choice among attainable combinations of price and output increases in coming quarters. With the effects of past excessive total demand still working through the economy, a period of relatively slow advances in output is probably necessary to complete the adjustment from the accelerating inflation experienced since 1965. If the most likely length of this correction process is not taken into account in the determination of stabilization actions, what might appear to be a strong recovery, resulting from stimulative monetary and fiscal actions, would prove only temporary. The adjustment process involved in unwinding from the 1965-69 inflation can be expected to be long and painful, but it may be even more painful if not consistently pursued.

Estimates made by this Bank indicate that if Federal expenditures grew at a 5 to 6 per cent annual rate and the money stock were increased at a 5 per cent rate from the quarter ending in June, the growth rate of total spending would most likely be about 5 to 6 per cent in the year ending in mid-1971, and 7 to 8 per cent in the following year (Table II) ${ }^{1}$.
Real product would grow moderately in the coming year, then increase at about a 3.5 per cent rate in the year ending in mid-1972. Such a policy would most likely result in the rate of increase in prices being down to about 3.5 per cent by mid-1972.

A slower rate of growth of money, for example 3 per cent, would probably result in a more moderate 4 per cent advance of total spending in the coming year, about the same as in the first half of 1970 . From mid-1971 through mid-1972, total spending would increase about 5 per cent. Real product, under such a policy, would most likely decline slightly through mid1971, then increase slowly in the following year. Such total spending growth would probably reduce the rate of inflation to below 3 per cent by mid-1972.

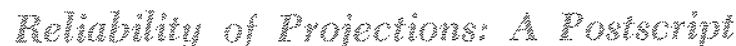

Economic forecasting based on econometric models continues to be imprecise, and information concerning the past forecasting performance of a given model should be carefully considered before such a model is used as a guide in policy formulation. To assist the reader in forming his own judgment about the reliability of projections based on research conducted at this Bank, some comparisons are presented to cast light on the model's forecasting reliability.

To examine the reliability of projections, the equam tions of the model were estimated using the experi-

\footnotetext{
tSee "A Monetarist Model for Economic Stabilization," this Review (April 1970), pp. 7-25.
} 


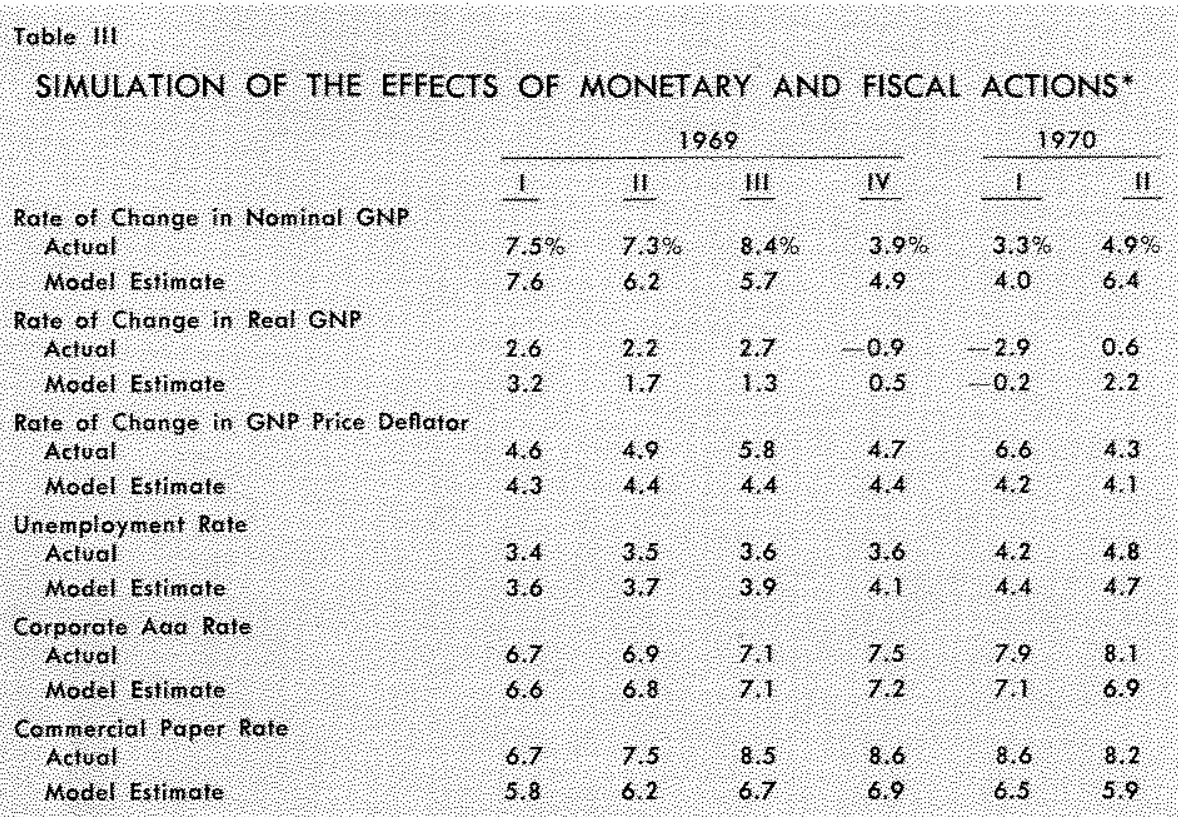

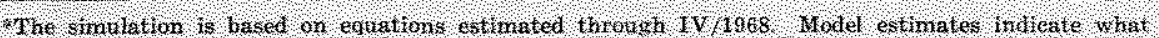

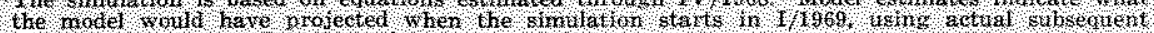
changes in nonet and biblenployment expenditares.

ence of the period from 1953 through 1968. Observations since the beginning of 1969 can then be used to gauge the performance of the model in simulating the effects of monetary and fiscal actions in 1969 and 1970. For 1969 and 1970, observed monetary and fiscal developments were treated as if they were known in advance to the forecaster; thus forecasts of these policy variables were not considered as a factor contributing to error in the projections.

The results of this simulation experiment are shown in Table III. Observed values for the variables are shown along with model estimates. Econometric model-building has not yet progressed to the point where the models are able to capture accurately quarter-to-quarter movements in the variables. What is important in assessing forccasting reliability is the degree to which marked and sustained over-or underestimation is avoided.

Examination of the forecasts of total spending for 1969 and the first half of 1970 indicates that the model succeeded in projecting the pattern of total spending growth. The model underestimated the increase of total spending in the second and third quarters of 1969, and overestimated the change in succeeding quarters. For the six quarters as a whole, total spending increased at a 5.9 per cent average annual rate, while the model projected a 5.8 per cent rate of increase.

Model forecasts of real output change also tracked actual movements quite closely on average. Real out- put change corresponded closely to total spending change, and the model succeeded in producing that similarity of movement. For the six-quarter period, total output increased at a 0.7 per cent average annual rate; the model estimated a 1.4 per cent average rate.

Forecasting the course of prices, which has been a prime concern in the U.S. economy in recent years, did not satisfy the criterion of avoiding over-or under-estimation. The model did succeed in that it did not project any decline in the rate of price advance before 1970 , though it did not succeed in projecting the degree to which inflation accelerated in 1969 and early 1970.

The upward movement of unemployment as a percentage of the labor force in 1969 and 1970 was projected by the model, though the increase was over-estimated in 1969. The long-term interest rate was tracked very closely by the model in 1969 , but the projections fell below the actual rates in the first half of 1970 . Since only two quarters have transpired yielding these discrepancies between actual and predicted, it is probably too early to form a judgment as to whether the criterion of marked and sustained overor underestimation is violated. The short-term interest rate was consistently underestimated by the model, though the pattern of increasing through 1969 and then declining in 1970 was projected by the model.

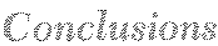

A continuing period of uncomfortable adjustment to reduced inflation may be in prospect for the U.S. economy. Given Federal budget plans for fiscal 1971, stimulative monetary actions could bolster output and employment, but any significant gains in the battle against inflation would be sacrificed. On the other hand, more restrictive actions aimed at reducing the inflation rate rapidly would probably give rise to further cutbacks in output and employment.

Projections based on research at this Bank appear to be most reliable with respect to growth of total spending. Projections of the other variables of the model, though useful and informative, should be accepted tentatively, Additional observations will provide further basis for a judgment about the reliability of model projections for these variables. 